\title{
Impact of cardiovascular risk factors on the clinical presentation and survival of pulmonary embolism without identifiable risk factor
}

\author{
Nuria Rodríguez-Núñez ${ }^{1}$, Alberto Ruano-Raviña ${ }^{2,3}$, Adriana Lama ${ }^{1}$, Lucía Ferreiro ${ }^{1,4}$, Jorge Ricoy ${ }^{1}$, \\ José M. Álvarez-Dobaño ${ }^{1,4}$, Juan Suárez-Antelo ${ }^{1}$, M. Elena Toubes ${ }^{1}$, Carlos Rábade ${ }^{1}$, Antonio Golpe ${ }^{1,4}$, \\ Tamara Lourido ${ }^{1}$, Francisco Javier González-Barcala ${ }^{1,4}$, Luis Valdés ${ }^{1,4}$ \\ ${ }^{1}$ Department of Pulmonology, Complejo Hospitalario Universitario de Santiago, Santiago de Compostela, Spain; ${ }^{2}$ Department of Preventive \\ Medicine and Public Health, Universidad de Santiago de Compostela, Santiago de Compostela, Spain; ${ }^{3}$ CIBER of Epidemiology and Public Health, \\ CIBERESP, Madrid, Spain; ${ }^{4}$ Interdisciplinary Research Group on Pulmonology, Instituto de Investigaciones Sanitarias de Santiago (IDIS), Santiago \\ de Compostela, Spain \\ Contributions: (I) Conception and design: N Rodríguez-Núñez, A Ruano-Raviña, L Valdés; (II) Administrative support: N Rodríguez-Núñez, A \\ Ruano-Raviña, A Lama; (III) Provision of study materials or patients: N Rodríguez-Núñez, A Lama, L Ferreiro, J Ricoy, JM Álvarez-Dobaño, J \\ Suárez-Antelo, ME Toubes, C Rábade, A Golpe, T Lourido, FJ González-Barcala; (IV) Collection and assembly of data: N Rodríguez-Nuñez, A \\ Ruano-Raviña, L Valdés; (V) Data analysis and interpretation: N Rodríguez-Nuñez, A Ruano-Raviña, L Valdés; (VI) Manuscript writing: All authors; \\ (VII) Final approval of manuscript: All authors. \\ Correspondence to: Prof. Dr. Alberto Ruano-Raviña. Department of Preventive Medicine and Public Health, Universidad de Santiago de Compostela, \\ 15782 Santiago de Compostela, Spain. Email: alberto.ruano@usc.es.
}

Background: The nature of pulmonary embolism (PE) without identifiable risk factor (IRF) remains unclear. The objective of this study is to investigate the potential relationship between cardiovascular risk factors (CVRFs) and PE without IRF (unprovoked) and assess their role as markers of disease severity and prognosis.

Methods: A case-control study was performed of patients with PE admitted to our hospital [2010-2019]. Subjects with PE without IRF were included in the cohort of cases, whereas patients with PE with IRF were allocated to the control group. Variables of interest included age, active smoking, obesity, and diagnosis of arterial hypertension, dyslipidemia or diabetes mellitus.

Results: A total of 1,166 patients were included in the study, of whom $64.2 \%$ had PE without IRF. The risk for PE without IRF increased with age [odds ratio (OR): 2.68; 95\% confidence interval (CI): 1.95-3.68], arterial hypertension (OR: 1.63; 95\% CI: 1.27-2.07), and dyslipidemia (OR: 1.63; 95\% CI: 1.24-2.15). The risk for PE without IRF was higher as the number of CVRF increased, being 3.99 (95\% CI: 2.02-7.90) for subjects with $\geq 3$ CVRF. The percentage of high-risk unprovoked PE increased significantly as the number of CVRF rose [0.6\% for no CVRF; 23.8\% for a CRF, P<0.001 (OR: 9.92; 95\% CI: 2.82-34.9); 37.5\% for two CRFs, $\mathrm{P}<0.001$ (OR: 14.8; 95\% CI: 4.25-51.85); and 38.1\% for $\geq 3, \mathrm{P}<0.001$ (OR: 14.1; 95\% CI: 4.06-49.4)]. No significant differences were observed in 1-month survival between cases and controls, whereas differences in 24-month survival reached significance.

Conclusions: A relationship was observed between CVRF and PE without IRF, as the risk for unprovoked $\mathrm{PE}$ increased with the number of CVRF. In addition, the number of CVRF was associated with PE without IRF severity, but not with prognosis.

Keywords: Pulmonary embolism (PE); unprovoked pulmonary embolism (unprovoked PE); no identifiable risk factor (no IRF); venous thromboembolism; cardiovascular risk factors (CVRFs); severity; mortality

Submitted Apr 10, 2020. Accepted for publication Aug 28, 2020.

doi: $10.21037 /$ jtd-20-1634

View this article at: http://dx.doi.org/10.21037/jtd-20-1634

(c) Journal of Thoracic Disease. All rights reserved. 


\section{Introduction}

Acute pulmonary embolism (PE) is a life-threatening disease that occurs in a wide variety of clinical settings (1), with an incidence of $0.6-1.83$ cases/1,000 (2-4). PE is a multifactorial disease induced by the complex interaction between congenital and acquired risk factors, with 50-60\% of patients exhibiting risk factors (5-8). The absence of triggering factors in thrombotic events increases the risk of recurrence and determines the decision to prescribe longterm anticoagulant therapy $(9,10)$.

Little is known about the characteristics of patients with PE without identifiable risk factor (IRF) [previously named unprovoked or idiopathic PE (11)]. A number of authors identify unprovoked $\mathrm{PE}$ as a first sign of an unknown cancer (12). Although PE occurs in end-stage cancer, it may also appear prior to tumor progression. It is estimated that 1 in 20 patients who suffer a PE without IRF event will be diagnosed with cancer 1 year after the PE event (13). The role of other risk factors is more controversial. An isolated factor alone may not be sufficient to cause PE, but it is the co-occurrence of several factors what may induce the disease (14). In the last years, factors considered irrelevant in the past [as cardiovascular risk factors (CVRFs) for atherosclerosis (15-18), inflammatory diseases (19), and other diseases (5)] have been found to play a relevant role in a variety of conditions. Thus, a co-morbidity may be linked to PE, which means that a PE that would be identified as unprovoked is actually a PE with IRF (8).

The objectives of this study are to assess the characteristics of patients diagnosed with PE without IRF after admission for symptomatic acute PE (I) to determine whether CVRF are new risk factors for PE; and (II) to establish the role of CVRF in the assessment of disease severity and prognosis.

We present the following article in accordance with the STROBE reporting checklist (20) (available at http://dx.doi. org/10.21037/jtd-20-1643).

\section{Methods}

The study was conducted in a tertiary university hospital with over 1,000 beds serving a population of 450,000. A nested case-control study was performed in patients admitted for PE between January 2010 and September 2019. A consecutive sampling was used to collect data from patients with acute $\mathrm{PE}$ admitted to our hospital during the study period.
$\mathrm{PE}$ diagnosis was confirmed in the presence of a ventilation/perfusion scintigraphy demonstrating a high clinical probability of $\mathrm{PE}$, according to Prospective Investigation of the Pulmonary Embolism Diagnosis criteria (21), the presence of proximal deep vein thrombosis (DVT) in the lower limbs confirmed by compression ultrasonography in patients with inconclusive findings on ventilation/perfusion scintigraphy (22); or a diagnosis of acute PE by helical contrast-enhanced computed tomography of the thorax (23). Cases were identified by the detection of codes on hospital discharge reports. Subjects younger than 18 and patients admitted for causes other than PE who developed PE as an in-hospital complication during hospitalization were excluded. Length of stay was determined based on the electronic discharge report.

For the case-control study, subjects with PE without IRF (unprovoked PE) were considered a case in the following settings: PE in the absence of known active cancer, pregnancy, use of hormone contraceptives, thrombophilia (either hereditary or acquired), or a transient risk factor within the last 3 months, including palsy, paresis or lowerlimb immobilization, hospitalization $\geq 3$ days, or major surgery. All subjects meeting some of these factors were considered to have PE with IRF (provoked PE) and were included in the control group. This method of classification has already been used in previous case-control studies (18). Thrombophilia testing was performed in accordance with the local protocol after the acute phase of PE; in patients younger than 55 years without IRFs for venous thromboembolic (VTE); in patients with recurrent VTE or unusual VTE location.

CVRF included (18) age ( $>50$ in men and 60 in women); active smoking (one or more daily cigarettes); obesity (BMI $>30 \mathrm{~kg} / \mathrm{m}^{2}$ ); and a diagnosis of arterial hypertension (24), dyslipidemia (25) or diabetes mellitus.

\section{Initial selection of variables}

The selected variables included sex, age, active smoking; presence of chronic lung disease; heart failure; hypertension; diabetes mellitus; dyslipidemia; obesity; previous cerebrovascular accident; varicose veins; previous VTE disease; simplified pulmonary embolism severity index (PESIs) (26); degree of dyspnea [modified from the Medical Research Council (27)], the last two variables being also strongly associated with the length of hospital stay (28); Charlson index (29); date of PE diagnosis; time of initiation of coumarin anticoagulant therapy; presence 


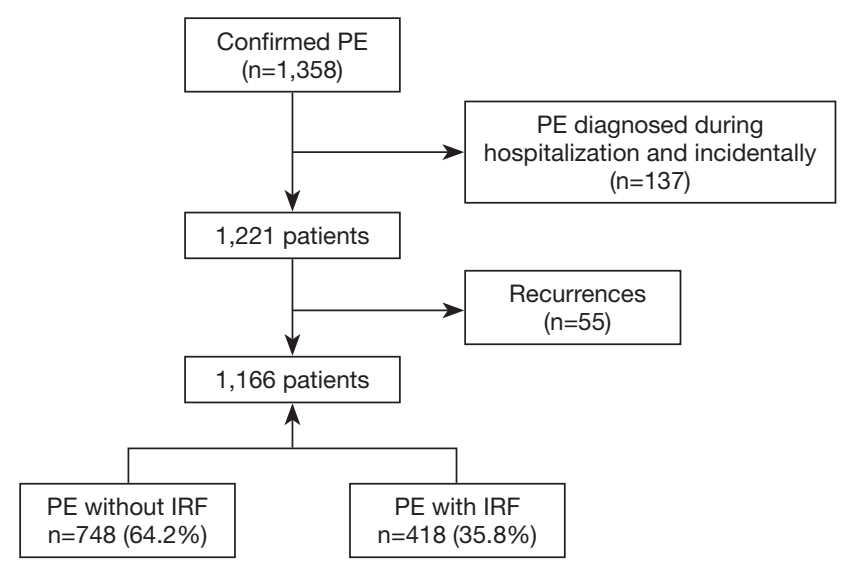

Figure 1 Patient flowchart. PE, pulmonary embolism; IRF, identifiable risk factor.

of anemia (defined as hemoglobin $<13 \mathrm{~g} / \mathrm{dL}$ for men and $<12 \mathrm{~g} / \mathrm{dL}$ for women); platelet elevation; fibrinogen; erythrocyte sedimentation rate (ESR) and leukocytes $(>350,000 / \mu \mathrm{L},>400 \mathrm{mg} / \mathrm{dL},>30 \mathrm{~mm}$ and $>11,000 \mathrm{cell} / \mu \mathrm{L}$, respectively); neutrophil count in blood (percentage); C-reactive protein; troponin; N-terminal pro-B-type natriuretic peptide; and length of hospital stay (in days).

\section{Ethical statement}

The study was conducted in accordance with the Declaration of Helsinki (as revised in 2013). The study was approved by the Institutional Review Board of the Health District (registration code 2018/299) and informed consent was taken from all the patients.

\section{Statistical analysis}

Once patients with idiopathic PE had been identified, a bivariate descriptive analysis was performed to assess the characteristics of cases and controls (sex, age, and the presence of comorbidities by general families of diseases (respiratory, circulatory, to name a few). Data on parameters potentially associated with $\mathrm{PE}$ were also collected. A new bivariate analysis was conducted to compare the clinical presentation of PE between cases and controls. Raw and adjusted logistic regression was used to calculate the probability of being a case or control based on the presence or absence of CVRF, using PE without IRF (case) and PE with IRF (control) as the dependent variables, and taking each CVRF as an independent variable. Age, gender, other co-variables and all risk factors were considered for multivariate analysis. Then, comorbidities were grouped to determine the number of comorbidities present in each study subject and calculate the likelihood of being a case or a control as a function of the number of comorbidities. Subjects without any CVRF were used as a reference. PE severity was determined by PESIs. The likelihood that PE was more severe as the number of CVRFs increased was calculated, and a comparison of cases versus controls was performed. Results of logistic regression were expressed as odds ratio (OR) with $95 \%$ confidence intervals (CIs). Finally, differences in 30-day and 2-year survival between subjects with provoked and unprovoked PE were assessed. Long-rank test was performed to compare the survival curves of the two types of PE. Statistical analyses were carried out using either IBM SPSS Statistics v22 or the free $\mathrm{R}$ software package.

\section{Results}

A total of 1,358 episodes of PE were confirmed during the study period (Figure 1), of which 137 were excluded since they corresponded to patients with incidental PE and 55 corresponded to patients with recurrent PE. Of the 1,166 patients included in the final sample, $748(64.2 \%)$ had a diagnosis of unprovoked $\mathrm{PE}$, as subjects did not have risk factors for VTE.

Table 1 displays the demographic characteristics and comorbidities of patients by group (cases and controls). $\mathrm{PE}$ with and without IRF were more frequent in women (59\%), although differences were not significant. An older age $(\mathrm{P}<0.001)$, arterial hypertension $(\mathrm{P}<0.001)$, dyslipidemia $(\mathrm{P}=0.001)$ and varicose veins/chronic venous insufficiency $(\mathrm{P}=0.039)$ were more frequent in patients with unprovoked $\mathrm{PE}$, as compared to provoked $\mathrm{PE}$. In addition, the difference in the proportion of patients with diabetes mellitus in the cohort of cases was close to significance $(\mathrm{P}=0.051)$. The presence of comorbidities was significantly more frequent in the cohort of cases (Charlson index; $\mathrm{P}<0.001$ ), and all-cause mortality in patients with $\mathrm{PE}$ without IRF was significantly lower than in controls $(\mathrm{P}<0.001)$.

Table 2 summarizes the clinical characteristics of patients by type of PE (with $v s$. without IRF). No significant differences were observed in risk according to PESIs scale. The proportion of patients with saturation $<90 \%$ was higher in the cohort of cases $(\mathrm{P}=0.047)$. In contrast, the control group exhibited a higher sedimentation rate in blood (provoked $\mathrm{PE})(\mathrm{P}<0.001)$ and had thrombocytosis 
Table 1 Comparative study of subjects with PE without IRF (cases) $v s$. PE with IRF (controls)

\begin{tabular}{|c|c|c|c|}
\hline Variables & Cases, n (\%) & Controls, n (\%) & $P$ value \\
\hline Sex & & & 0.736 \\
\hline Woman & $446(59.6)$ & $245(58.6)$ & \\
\hline Age & & & $<0.001$ \\
\hline Median & 76 & 69 & \\
\hline 25th-75th percentile & $66-83$ & $54-78$ & \\
\hline Length of stay & & & 0.127 \\
\hline Median & 7 & 7 & \\
\hline 25th-75th percentile & $5-11$ & $5-11$ & \\
\hline Exitus & $182(24.3)$ & $142(34.0)$ & $<0.001$ \\
\hline Cause of death & & & 0.138 \\
\hline PE & $28(15.6)$ & $14(9.9)$ & \\
\hline Other causes & $152(84.4)$ & $127(90.1)$ & \\
\hline Smoking habits & & & 0.015 \\
\hline Smoker & $59(7.9)$ & $48(11.6)$ & \\
\hline Ex-smoker & $96(12.9)$ & $69(16.6)$ & \\
\hline Never-smoker & 591 (79.2) & $298(71.8)$ & \\
\hline Arterial hypertension & $407(54.4)$ & $177(42.3)$ & $<0.001$ \\
\hline Diabetes mellitus & $115(15.4)$ & $47(11.2)$ & 0.051 \\
\hline Dyslipidemia & $240(32.1)$ & $94(22.5)$ & 0.001 \\
\hline Obesity & $166(29.7)$ & $72(23.8)$ & 0.061 \\
\hline Varicose veins & $94(12.6)$ & $36(8.6)$ & 0.039 \\
\hline Previous stroke & $46(6.2)$ & $21(5.0)$ & 0.425 \\
\hline Previous PE/DVT & $106(14.2)$ & $37(8.9)$ & 0.08 \\
\hline Heart failure & $49(6.6)$ & $18(4.3)$ & 0.114 \\
\hline Chronic lung disease & $100(13.4)$ & $46(11.0)$ & 0.242 \\
\hline Charlson & & & $<0.001$ \\
\hline $0-1$ & $581(77.8)$ & $231(55.5)$ & \\
\hline 2 & 94 (12.6) & 78 (18.7) & \\
\hline$\geq 3$ & 72 (9.6) & $108(25.8)$ & \\
\hline
\end{tabular}

$\mathrm{PE}$, pulmonary embolism; IRF, identifiable risk factor; DVT, deep vein thrombosis.

$(\mathrm{P}<0.001)$ and anemia $(\mathrm{P}<0.001)$.

Univariate analysis revealed that the individual risk of PE without IRF increased significantly with an older age (OR: 2.68; 95\% CI: 1.95-3.68) arterial hypertension (OR:
1.63; 95\% CI: 1.27-2.07) and dyslipidemia (OR: 1.63; 95\% CI: 1.24-2.15). The correlation between age (OR: 2.32; 95\% CI: 1.56-3.43) and arterial hypertension (OR: 1.50; 95\% CI: $1.09-2.08)$ remained significant in multivariate analysis (Table 3). The risk for PE without IRF increased as the number of CVRF rose, and the risk of PE without IRF increased significantly with the presence of a CVRF (OR: 2.40; 95\% CI: 1.28-4.52), and reached an OR of 3.99 (95\% CI: 2.2-7.90) for the presence of three or more CVRF (Table 3).

The distribution of patients by number of CVRF was analyzed. The percentage of high-risk PE without IRF was significantly higher as the number of CVRF increased [0.6\% for no CVRF; $23.8 \%$ for a CVRF, $\mathrm{P}<0.001$ (OR: 9.92; 95\% CI: 2.82-34.9); $37.5 \%$ for two CVRFs, $\mathrm{P}<0.001$ (OR: 14.8 ; 95\% CI: $4.25-51.85$ ) and $38.1 \%$ for $\geq 3, \mathrm{P}<0.001$ (OR: 14.1 ; 95\% CI: 4.06-49.4)] (Table 4).

Figure 2 shows the same data expressed as number of patients instead of percentages, as compared to $\mathrm{PE}$ with IRF. Unlike PE without IRF, an increase in the number of CVRF was not found to be associated with a higher number of patients with high-risk PE.

No significant differences were observed in 30-day survival between PE without IRF (27 cases; $3.6 \%$ ) and PE with IRF (23 patients; $5.5 \%)(\mathrm{P}=0.127)$. All deceased patients with PE without IRF (27) had a PESIs $\geq 1$ (high risk) $(5.4 \%$; $\mathrm{P}>0.001$ between low-risk and high-risk PESIs). Of the 23 deceased patients with PE with IRF, only $1(0.7 \%)$ had a PESIs of 0 (low risk) vs. 22 (7.9\%) with high risk $(\mathrm{P}=0.003)$.

Statistically significant differences were observed in 24-month survival between PE without IRF (118 cases; $15.8 \%)$ and PE with IRF (109 patients; $26.1 \%)(\mathrm{P}<0.001)$ (Figure $3 A$ ). Figure $3 B$ contains the 2 -year survival curve for patients with PE without IRF and without CVRF (21 cases) vs. patients with some CVRF (727). Although there was no mortality among the former, a total of 118 patients died (16.2\%), but differences were not significant $(\mathrm{P}=0.053)$. No relationship was documented between mortality and the presence of CVRF in patients with $\mathrm{PE}$ without IRF ( $\mathrm{P}=0.258)$ (Figure 3C).

\section{Discussion}

The results of this study demonstrate a relationship between CVRFs and PE without IRFs, with this association being stronger as the number of CVRFs increased. In addition, there was a statistically significant relationship between the 
Table 2 Clinical presentation of PE without IRF vs. PE with IRF

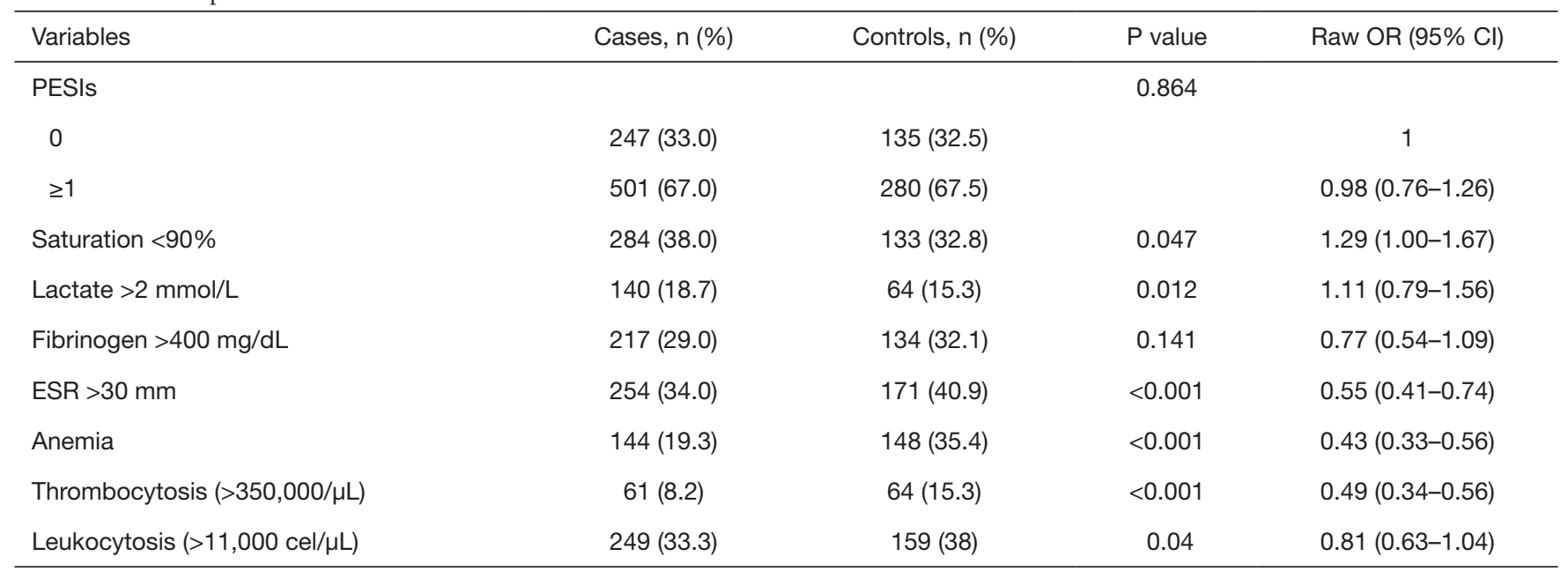

$\mathrm{PE}$, pulmonary embolism; IRF, identifiable risk factor; OR, odds ratio; Cl, confidence interval; PESIs, simplified pulmonary embolism severity index; ESR, erythrocyte sedimentation rate.

Table 3 Univariate and multivariate analysis of factors associated with PE with IRF vs. PE without IRF

\begin{tabular}{|c|c|c|c|}
\hline Variables & Raw OR (95\% Cl) & $\begin{array}{c}\text { Adjusted OR } \\
(95 \% \mathrm{Cl})\end{array}$ & $P$ value \\
\hline Sex & & & 0.754 \\
\hline Man & 1 & 1 & \\
\hline Woman & $1.04(0.81-1.33)$ & $0.95(0.70-1.29)$ & \\
\hline Age & & & $<0.001$ \\
\hline $\begin{array}{l}>50 \text { men, >60 } \\
\text { women }\end{array}$ & 2.68 (1.95-3.68) & $2.32(1.56-3.43)$ & \\
\hline Arterial hypertension & $1.63(1.27-2.07)$ & $1.50(1.09-2.08)$ & 0.014 \\
\hline Diabetes mellitus & $1.43(0.99-2.06)$ & $1.11(0.69-1.80)$ & 0.656 \\
\hline Dyslipidemia & $1.63(1.24-2.15)$ & $1.26(0.89-1.78)$ & 0.192 \\
\hline Obesity & $1.36(0.97-1.87)$ & $1.34(0.95-1.89)$ & 0.098 \\
\hline Active smoking & $0.66(0.44-0.98)$ & $1.13(0.69-1.85)$ & 0.641 \\
\hline \multicolumn{4}{|l|}{$\begin{array}{l}\text { Cumulative number } \\
\text { of CVRF }\end{array}$} \\
\hline 0 & 1 & 1 & \\
\hline 1 & $3.29(1.89-5.72)$ & $2.40(1.28-4.52)$ & \\
\hline 2 & $5.48(3.15-9.53)$ & $3.74(1.93-7.25)$ & \\
\hline$\geq 3$ & $6.06(3.48-10.55)$ & 3.99 (2.02-7.90) & \\
\hline
\end{tabular}

$\mathrm{PE}$, pulmonary embolism; IRF, identifiable risk factor; OR, odds ratio; $\mathrm{Cl}$, confidence interval; CVRF, cardiovascular risk factor.
Table 4 Impact of CVRF on PE without IRF severity

\begin{tabular}{|c|c|c|c|c|}
\hline \multirow{3}{*}{$\begin{array}{l}\text { Cumulative } \\
\text { number of } \\
\text { CVRF }\end{array}$} & \multicolumn{4}{|c|}{ PE without IRF } \\
\hline & \multicolumn{2}{|c|}{ PESIs, n (\%) } & \multirow{2}{*}{ - $P$ value } & \multirow{2}{*}{ OR $(95 \% \mathrm{Cl})$} \\
\hline & Low risk & High risk & & \\
\hline 0 & $18(7.3)$ & $3(0.6)$ & & 1 \\
\hline 1 & $72(29.1)$ & $119(23.8)$ & $<0.001$ & 9.92 (2.82-34.9) \\
\hline 2 & $76(30.8)$ & $188(37.5)$ & $<0.001$ & $14.8(4.25-51.85)$ \\
\hline$\geq 3$ & $81(32.8)$ & $191(38.1)$ & $<0.001$ & $14.1(4.06-49.4)$ \\
\hline
\end{tabular}

number of CVRF and the severity of PE without IRF. To the best of our knowledge, this is the first study to assess the relationship between CVRFs and PE in Spain.

Although in a recent meta-analysis Mahmoodi et al. found no association between traditional modifiable CVRFs with an increased risk of VTE (30), there is evidence suggesting a possible association between VTE and CVRF. According to a study, the prevalence of atherosclerosis is significantly higher in patients with spontaneous VTE as compared to patients with VTE secondary to known risk factors and controls (15). Another study revealed that symptomatic atherosclerosis was more frequent in older patients with PE and was associated with poorer outcomes (higher hospital mortality and higher number of adverse 


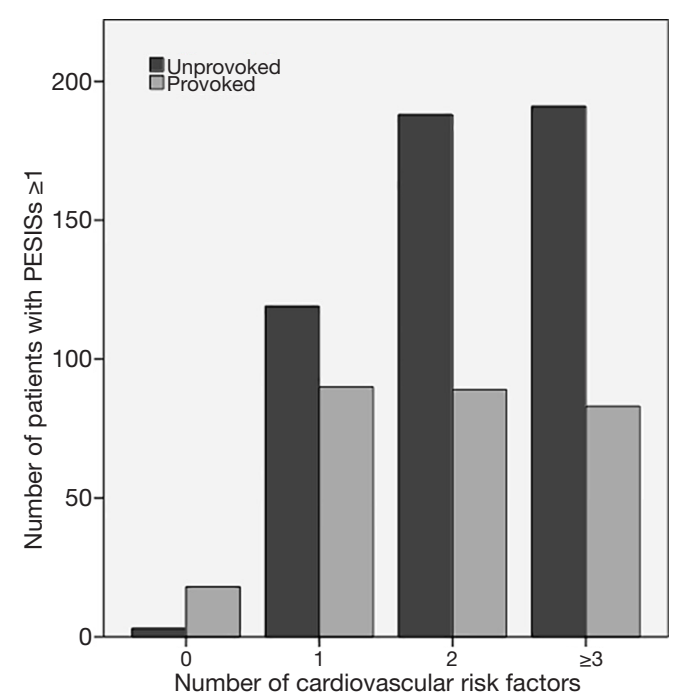

Figure 2 Number of patients with simplified PESI $\geq 1$ (high risk) as a function of the number of CVRFs in patients with PE without IRF vs. PE with IRF. PESI, pulmonary embolism severity index; CVRF, cardiovascular risk factor; PE, pulmonary embolism; IRF, identifiable risk factor.

events in in-patients with PE) (31). The long-term incidence of cardiovascular disease is higher in patients with idiopathic VTE than in patients with a secondary VTE $(32,33)$. A meta-analysis of 21 studies involving 63,552 patients revealed that the risk for VTE was higher in patients with obesity, arterial hypertension and diabetes mellitus (34). A study conducted in Copenhagen showed that obesity and smoking - but not dyslipidemia or diabetes mellituswere risk factors for VTE (35). These results are consistent with those obtained in a recent study in more than 700,000 patients, which showed that obesity, smoking and an advanced age are associated with a higher risk for VTE (36). In a large population-based study with a sample of more than 6 million people, obesity was found to be strongly associated with PE after adjustment for age and other risk factors. The study period was 10 years, which suggests a negative effect on the cardiopulmonary system (37). Gaertner et al. carried out a 6-month follow-up study in 515 patients with PE [325 (63\%) with PE without IRF] and documented a statistically significant relationship between age, diabetes mellitus and the cumulative number of CVRF with a higher risk for PE without IRF (18).

Our results $[1,166$ patients; $748(64 \%)$ with a PE without IRF and 24-month follow-up] are in agreement with current knowledge, as it shows a statistically significant

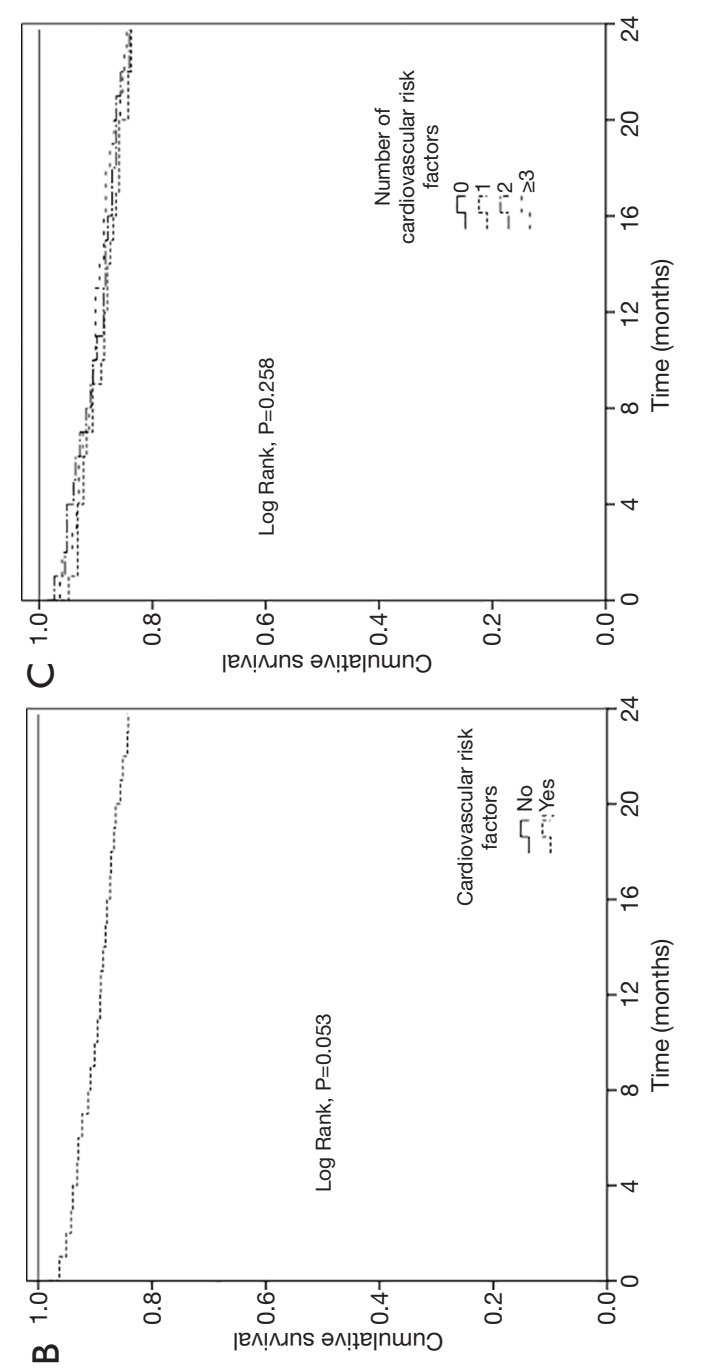

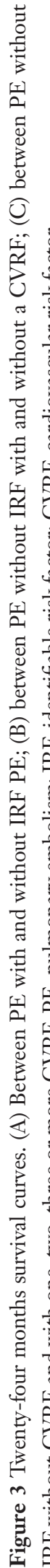


relationship between age and arterial hypertension and a higher risk for PE without IRF (OR: 2.32; 95\% CI: 1.563.43 and OR: 1.50; 95\% CI: 1.09-2.08, respectively) and severity. In contrast, its association with diabetes mellitus and obesity did not reach significance, although it remained close $(\mathrm{P}=0.051$ and 0.061 , respectively). In agreement with the results obtained by Gaertner et al. (18), the proportion of high-risk unprovoked PE, as assessed by PESIs, increased significantly as the number of CVRF increased, which was not observed in provoked PE. Two-year mortality was significantly higher in $\mathrm{PE}$ with IRF as compared to $\mathrm{PE}$ without IRF $(26.1 \%$ vs. $15.8 \%$; $\mathrm{P}<0.001)$, which can be explained by the fact that patients in the control group had a significantly higher Charlson index and 141 (33.7\%) had an active neoplasm. No significant differences were observed in mortality between patients with PE without IRF and without CVRFs (21 patients; 0 deaths) and with CVRF [727; 118 deaths $(16.2 \%) ;(\mathrm{P}=0.053)$ ], probably due to the small number of patients without CVRF.

The results obtained in this study suggest that the presence of CVRF increases the risk for PE without IRF. According to the literature, patients with CVRF have an inflammatory and hypercoagulable status that may predispose patients to develop VTE. Petrauskiene et al. reported that the risk for VTE adjusted for age doubled the one reported for non-diabetic patients (38). However, an association was not observed between VTE and PE without IRF, diabetes mellitus is an inflammatory disease that may cause dyslipidemia (which is associated with hypercoagulation, endothelial dysfunction and increased platelet aggregation), hypertension and abnormal coagulation $(39,40)$. Observational studies have demonstrated an association between dyslipidemia and VTE $(39,41)$. Therefore, these risk factors may be involved in the underlying process of the disease and be associated with VTE.

The present study has some limitations. One of them is its sample size, which is relatively small when we want to test the effect of certain variables present with low frequency (such as obesity and diabetes). A further limitation is that we have not included all possible CVRFs (i.e., renal function or arterial stiffness), which might have a certain role on PE. We have not included information that could be useful when stratifying the risk patients suffering PE such as right ventricle dilatation by CT scan or echocardiography, or blood biomarkers. On the other hand, it is striking that we have not observed a relevant increasing in the ORs of unprovoked PE when the accumulated number of risk factors turns from two to three, but we have no explanation for this observation.

The relationship between CVRF and PE without IRF is very relevant. At present, $\mathrm{PE}$ is classified as unprovoked in the absence of risk factors such as neoplasm, pregnancy, trauma, surgery, immobilization or some diseases. If the relationship between CVRFs and PE is demonstrated, this would lead to the development of new strategies for the prevention of VTE. These patients should be recommended to lose weight, and patients should be interrogated about the use of some therapies (antihypertensives, anti-platelet or lipid-lowering therapies) to reduce the risk for VTE.

The mortality rates obtained confirm that the PESIs scale identifies acute PE patients with a low risk for adverse events in the short term, including death. Only a low-risk patient died in each group (cases and controls) within the first 30 days after a diagnosis of $\mathrm{PE}(0.3 \%)$ vs. 49 deaths $(6.3 \%)$ in patients with PESIs $\geq 1(\mathrm{P}<0.001)$. These results are consistent with previous studies validating the original and simplified version of PESI $(26,42)$ and confirm that the identification of low-risk patients guides therapeutic decisions, as it establishes an initial management for each setting and can lead clinicians consider early discharge or prescribing an ambulatory treatment to low-risk patients.

In conclusion, we observed a relationship between CVRF and PE without IRFs, as the risk for PE without IRF increased with the number of CVRF. In addition, the number of CVRF was associated with PE without IRF severity, but not with prognosis.

\section{Acknowledgments}

Funding: None.

\section{Footnote}

Reporting Checklist: The authors have completed the STROBE reporting checklist. Available at http://dx.doi. org/10.21037/jtd-20-1634

Data Sharing Statement: Available at http://dx.doi. org/10.21037/jtd-20-1634

Peer Review File: Available at http://dx.doi.org/10.21037/jtd20-1634

Conflicts of Interest: All authors have completed the ICMJE uniform disclosure form (available at http://dx.doi. 
org/10.21037/jtd-20-1634). The authors have no conflicts of interest to declare.

Ethical Statement: The authors are accountable for all aspects of the work in ensuring that questions related to the accuracy or integrity of any part of the work are appropriately investigated and resolved. The study was conducted in accordance with the Declaration of Helsinki (as revised in 2013). The study was approved by the Institutional Review Board of the Health District (registration code 2018/299) and informed consent was taken from all the patients.

Open Access Statement: This is an Open Access article distributed in accordance with the Creative Commons Attribution-NonCommercial-NoDerivs 4.0 International License (CC BY-NC-ND 4.0), which permits the noncommercial replication and distribution of the article with the strict proviso that no changes or edits are made and the original work is properly cited (including links to both the formal publication through the relevant DOI and the license). See: https://creativecommons.org/licenses/by-nc-nd/4.0/.

\section{References}

1. Goldhaber SZ, Visani L, De Rosa M. Acute pulmonary embolism: clinical outcomes in the International Cooperative Pulmonary Embolism Registry (ICOPER). Lancet 1999;353:1386-9.

2. Konstantinides SV, Torbicki A, Agnelli G, et al. 2014 ESC guidelines on the diagnosis and management of acute pulmonary embolism. Eur Heart J 2014;35:3033-69, 3069a-3069k.

3. Heit JA, Silverstein MD, Mohr DN, et al. Risk factors for deep vein thrombosis and pulmonary embolism: a population-based case-control study. Arch Intern Med 2000;160:809-15.

4. Oger E. Incidence of venous thromboembolism: a community-based study in Western France. EPI-GETBP Study Group. Groupe d'Etude de la Thrombose de Bretagne Occidentale. Thromb Haemost 2000;83:657-60.

5. Riva N, Donadini MP, Ageno W. Epidemiology and pathophysiology of venous thromboembolism: similarities with atherothrombosis and the role of inflammation. Thromb Haemost 2015;113:1176-83.

6. Tagalakis V, Patenaude V, Kahn SR, et al. Incidence of and mortality from venous thromboembolism in a realworld population: the Q-VTE Study Cohort. Am J Med 2013;126:832.e13-21.

7. White RH. The epidemiology of venous thromboembolism. Circulation 2003;107:I4-8.

8. Kearon C, Ageno W, Cannegieter SC, et al. Categorization of patients as having provoked or unprovoked venous thromboembolism: guidance from the SSC of ISTH. J Thromb Haemost 2016;14:1480-3.

9. Baglin T, Luddington $\mathrm{R}$, Brown $\mathrm{K}$, et al. Incidence of recurrent venous thromboembolism in relation to clinical and thrombophilic risk factors: prospective cohort study. Lancet 2003;362:523-6.

10. Kyrle PA, Rosendaal FR, Eichinger S. Risk assessment for recurrent venous thrombosis. Lancet 2010;376:2032-9.

11. Konstantinides SV, Meyer G, Becattini C, et al. 2019 ESC Guidelines for the diagnosis and management of acute pulmonary embolism developed in collaboration with the European Respiratory Society (ERS). Eur Heart J 2020;41:543-603.

12. Goldberg RJ, Seneff M, Gore JM, et al. Occult malignant neoplasm in patients with deep venous thrombosis. Arch Intern Med 1987;147:251-3.

13. van Es N, Le Gal G, Otten HM, et al. Screening for occult cancer in patients with unprovoked venous thromboembolism: a systematic review and meta-analysis of individual patient data. Ann Intern Med 2017;167:410-7.

14. Rosendaal FR. Venous thrombosis: a multicausal disease. Lancet 1999;353:1167-73.

15. Prandoni P, Bilora F, Marchiori A, et al. An association between atherosclerosis and venous thrombosis. $\mathrm{N} \mathrm{Engl} \mathrm{J}$ Med 2003;348:1435-41.

16. Ridker PM, Danielson E, Fonseca FAH, et al. Rosuvastatin to prevent vascular events in men and women with elevated C-reactive protein. N Engl J Med 2008;359:2195-207.

17. Brighton TA, Eikelboom JW, Mann K, et al. Low-dose aspirin for preventing recurrent venous thromboembolism. N Engl J Med 2012;367:1979-87.

18. Gaertner S, Cordeanu EM, Mirea C, et al. Increased risk and severity of unprovoked venous thromboembolism with clustering cardiovascular risk factors for atherosclerosis: Results of the REMOTEV registry. Int J Cardiol 2018;252:169-74.

19. Tichelaar YIGV, Kluin-Nelemans HJC, Meijer K. Infections and inflammatory diseases as risk factors for venous thrombosis. A systematic review. Thromb Haemost 2012;107:827-37.

20. Vandenbroucke JP, von Elm E, Altman DG, et al. Strengthening the Reporting of Observational Studies in 
Epidemiology (STROBE): explanation and elaboration. PLoS Med 2007;4:e297.

21. PIOPED Investigators. Value of the ventilation/perfusion scan in acute pulmonary embolism. Results of the prospective investigation of pulmonary embolism diagnosis (PIOPED). JAMA 1990;263:2753-9.

22. Kearon C, Ginsberg JS, Hirsh J. The role of venous ultrasonography in the diagnosis of suspected deep venous thrombosis and pulmonary embolism. Ann Intern Med 1998;129:1044-9.

23. Remy-Jardin M, Remy J, Wattinne L, et al. Central pulmonary thromboembolism: diagnosis with spiral volumetric CT with the single-breath-hold technique-comparison with pulmonary angiography. Radiology 1992;185:381-7.

24. $2018 \mathrm{ESC}$ ESH Guidelines for the management of arterial hypertension. Rev Esp Cardiol (Engl Ed) 2019;72:160.

25. Catapano AL, Graham I, De Backer G, et al. Guía ESC/ EAS 2016 sobre el tratamiento de las dislipemias. Rev Esp Cardiol 2017;70:115.e1-64.

26. Jiménez D, Aujesky D, Moores L, et al. Simplification of the pulmonary embolism severity index for prognostication in patients with acute symptomatic pulmonary embolism. Arch Intern Med 2010;170:1383-9.

27. Mahler DA, Wells CK. Evaluation of clinical methods for rating dyspnea. Chest 1988;93:580-6.

28. Rodríguez-Núñez N, Ruano-Raviña A, Abelleira R, et al. Factors influencing hospital stay for pulmonary embolism. A cohort study. Arch Bronconeumol 2017;53:432-6.

29. Deyo RA, Cherkin DC, Ciol MA. Adapting a clinical comorbidity index for use with ICD-9-CM administrative databases. J Clin Epidemiol 1992;45:613-9.

30. Mahmoodi BK, Cushman M, Anne Næss I, et al. Association of traditional cardiovascular risk factors with venous thromboembolism: an individual participant data meta-analysis of prospective studies. Circulation 2017;135:7-16.

31. Keller K, Hobohm L, Münzel T, et al. Impact of symptomatic atherosclerosis in patients with pulmonary

Cite this article as: Rodríguez-Núñez N, Ruano-Raviña A, Lama A, Ferreiro L, Ricoy J, Álvarez-Dobaño JM, Suárez-Antelo J, Toubes ME, Rábade C, Golpe A, Lourido T, González-Barcala FJ, Valdés L. Impact of cardiovascular risk factors on the clinical presentation and survival of pulmonary embolism without identifiable risk factor. J Thorac Dis 2020;12(10):5411-5419. doi: 10.21037/jtd-20-1634 embolism. Int J Cardiol 2019;278:225-31.

32. Becattini C, Agnelli G, Prandoni P, et al. A prospective study on cardiovascular events after acute pulmonary embolism. Eur Heart J 2005;26:77-83.

33. Prandoni P, Ghirarduzzi A, Prins $\mathrm{MH}$, et al. Venous thromboembolism and the risk of subsequent symptomatic atherosclerosis. J Thromb Haemost 2006;4:1891-6.

34. Ageno W, Becattini C, Brighton T, et al. Cardiovascular Risk Factors and Venous Thromboembolism: A MetaAnalysis. Circulation 2008;117:93-102.

35. Holst AG, Jensen G, Prescott E. Risk factors for venous thromboembolism: results from the Copenhagen City Heart Study. Circulation 2010;121:1896-903.

36. Gregson J, Kaptoge S, Bolton T, et al. Cardiovascular risk factors associated with venous thromboembolism. JAMA Cardiol 2019;4:163-73.

37. Movahed MR, Khoubyari R, Hashemzadeh M, et al Obesity is strongly and independently associated with a higher prevalence of pulmonary embolism. Respir Investig 2019;57:376-9.

38. Petrauskiene V, Falk M, Waernbaum I, et al. The risk of venous thromboembolism is markedly elevated in patients with diabetes. Diabetologia 2005;48:1017-21.

39. Doggen CJM, Smith NL, Lemaitre RN, et al. Serum lipid levels and the risk of venous thrombosis. Arterioscler Thromb Vasc Biol 2004;24:1970-5.

40. Englyst NA, Taube JM, Aitman TJ, et al. A novel role for CD36 in VLDL-enhanced platelet activation. Diabetes 2003;52:1248-55.

41. Vayá A, Mira Y, Ferrando F, et al. Hyperlipidaemia and venous thromboembolism in patients lacking thrombophilic risk factors. Br J Haematol 2002;118:255-9.

42. Tamizifar B, Fereyduni F, Esfahani MA, et al. Comparing three clinical prediction rules for primarily predicting the 30-day mortality of patients with pulmonary embolism: The "Simplified Revised Geneva Score," the "Original PESI," and the "Simplified PESI." Adv Biomed Res 2016;5:137. 